\title{
The Role of Dislocation Channeling in IASCC Initiation of Neutron Irradiated Stainless Steel
}

\author{
Kale J. Stephenson ${ }^{\mathrm{a}}$, Gary S. Was ${ }^{\mathrm{a}}$
}

${ }^{a}$ University of Michigan, 2355 Bonisteel Blvd., Ann Arbor, MI, USA 48109-2104

Corresponding Author. phone: 1734936 0266, fax: 1734763 4540, email: kalejs@umich.edu

\begin{abstract}
This study intended to understand how dislocation channeling affects IASCC initiation using a novel four-point bend test. Stainless steels used in this study (irradiated in the BOR-60 reactor) included a commercial purity 304L alloy irradiated to 5.5, 10.2, and $47.5 \mathrm{dpa}$, and two high purity alloys, $\mathrm{Fe}-18 \mathrm{Cr}-$ $12 \mathrm{Ni}$ and $\mathrm{Fe}-18 \mathrm{Cr}-25 \mathrm{Ni}$, irradiated to $10 \mathrm{dpa}$. IASCC was enhanced by $\mathrm{MnS}$ inclusions, which dissolve in the NWC environment and form oxide caps, creating a crevice condition with a high propensity for crack initiation. Stress concentration at the grain boundary intersecting these sites induced crack initiation, resulting from discontinuous dislocation channels (DC). Stress to initiate IASCC decreased with dose due to earlier DC initiation. The HP Fe-18Cr-12Ni alloy had low IASCC susceptibility and the high Ni alloy did not crack. The difference was attributed to the propensity for DCs to transmit across grain boundaries, which controls stress accumulation at DC - grain boundary intersections.
\end{abstract}

\section{Introduction}

Irradiation-assisted stress corrosion cracking (IASCC) is a degradation mode that affects austenitic stainless steels (SS) in light water reactor (LWR) core internal components. IASCC occurs as a result of a combination of stress, a corrosive environment, and a susceptible material in the presence of an irradiation field. Irradiation causes microstructural changes (dislocation loop, precipitate, and void formation) and radiation-induced segregation (RIS) of solute elements at grain boundaries (GBs). However, isolating the cracking mechanism is difficult due to the simultaneous evolution of these features. 
Irradiation causes the deformation mode in SS to become highly localized, confined to narrow slip bands or dislocation channels (DCs). Intergranular (IG) cracks have been observed to initiate where DCs terminate at GBs [1-4]. These discontinuous DC - GB intersections are most likely to crack presumably because of high local stress buildup at the grain boundary [5-7]. Measurements of DC behavior in neutron irradiated SS are limited [8] as most IASCC tests result in complete failure of the sample, such as in a constant extension rate tensile (CERT) test or constant load test (CLT) [9-15]. IG cracks in these materials propagate rapidly after formation, causing failure with very low applied strain. Consequentially, the only metrics to describe SCC susceptibility are macroscopic parameters such as \%IG, total elongation, reduction in area, or fracture stress [16].

To better understand IASCC initiation, a novel four-point bend SCC experiment was developed [17,18]. The test creates a stress gradient through the sample thickness, slowing crack propagation and preserving the sample beyond initial crack formation. The four-point bend configuration also results in an area of nearly uniaxial tensile stress and strain, enhancing the possibility of observing multiple crack initiation sites on a single sample. Aside from small differences in the stress-strain state, the conditions of this experiment were meant to reproduce those used during previous CERT tests on the same alloys [16]. The primary objective of this study was to determine how DCs affect the IASCC initiation process by performing bend tests on several similar SSs to create crack initiation sites. Periodic unloading and inspection during the bend test procedure allowed loading conditions (stress and strain) and surface conditions (surface oxidation and DCs) to be monitored up to the point of IASCC initiation.

\section{Experiment}

\subsection{Alloys}

Three alloys were compared in this study: alloys AS, ES, and KS, with compositions shown in Table 1. Alloy AS is a commercial purity (CP) 304L SS, alloy ES is a high purity (HP) 18Cr-12Ni SS, and alloy $\mathrm{KS}$ is a high purity $18 \mathrm{Cr}-25 \mathrm{Ni}$ SS (alloy ES with Ni addition). Details regarding fabrication of these alloys can be found in ref. [19]. The average grain size of alloys AS, ES, and KS were $32 \pm 5 \mu \mathrm{m}, 29 \pm 4$ $\mu \mathrm{m}$, and $25 \pm 6 \mu \mathrm{m}$, respectively. Alloys AS and KS were confirmed to be solution annealed prior to irradiation, but a low density of deformation twins were observed in alloy ES, as shown in Fig. 1.

Inclusions were observed in each alloy as a result of processing, with average size and density reported in Table 2. Inclusions in alloy AS were relatively large (some had surface areas greater than $100 \mu \mathrm{m}^{2}$ ) and in irregular shapes as shown in Fig. 1d. Inclusions on alloy ES and KS surfaces were rarely larger than 10 $\mu \mathrm{m}^{2}$. Inclusion number density was similar for all alloys. 
Inclusion compositions were characterized using X-ray energy dispersive spectroscopy (XEDS) on an unirradiated sample of each alloy. Two types of inclusion were observed in alloy AS: MnS (possessing high amounts of $\mathrm{Mn}$ and $\mathrm{S}$ and a small amount of $\mathrm{Cr}$ ), and oxide inclusions (possessing relatively similar amounts of $\mathrm{Mn}, \mathrm{Cr}, \mathrm{Ti}, \mathrm{O}$ and trace amounts of $\mathrm{Al}$ ). $\mathrm{MnS}$ inclusions were typically larger than oxide inclusions ( $66 \mu \mathrm{m}^{2}$ vs. $25 \mu \mathrm{m}^{2}$, respectively, for 24 characterized inclusions). Inclusions in HP alloys ES and KS all were oxide inclusions (possessing $\mathrm{O}, \mathrm{Cr}$, and $\mathrm{Fe}$ with traces of $\mathrm{Mn}, \mathrm{Ni}$ and in some cases $\mathrm{Si}$ ).

Table 1. Chemical composition of alloys used in this study, in wt $\%$.

\begin{tabular}{cccccccccccccccccc}
\hline Heat ID & Material & Fe & Cr & Ni & Mn & Mo & Si & C & Ti & P & S & N & Nb & O & Co & Cu \\
\hline AS & SA CP 304L & bal. & 19.95 & 10.80 & 1.82 & 0.53 & 0.56 & 0.023 & 0.02 & 0.023 & 0.015 & 0.0720 & $<0.001$ & 0.011 & 0.22 & 0.29 \\
ES & SA HP 304L & bal. & 18.76 & 12.37 & 0.94 & 0.04 & 0.04 & 0.021 & 0.01 & $<0.01$ & 0.003 & 0.0003 & 0.005 & 0.004 & 0.01 & $<0.01$ \\
KS & SA HP 304L (+Ni) & bal. & 18.21 & 25.08 & 1.00 & 0.02 & 0.03 & 0.020 & 0.01 & $<0.01$ & 0.002 & 0.0005 & $<0.001$ & 0.003 & 0.01 & $<0.01$ \\
\hline
\end{tabular}
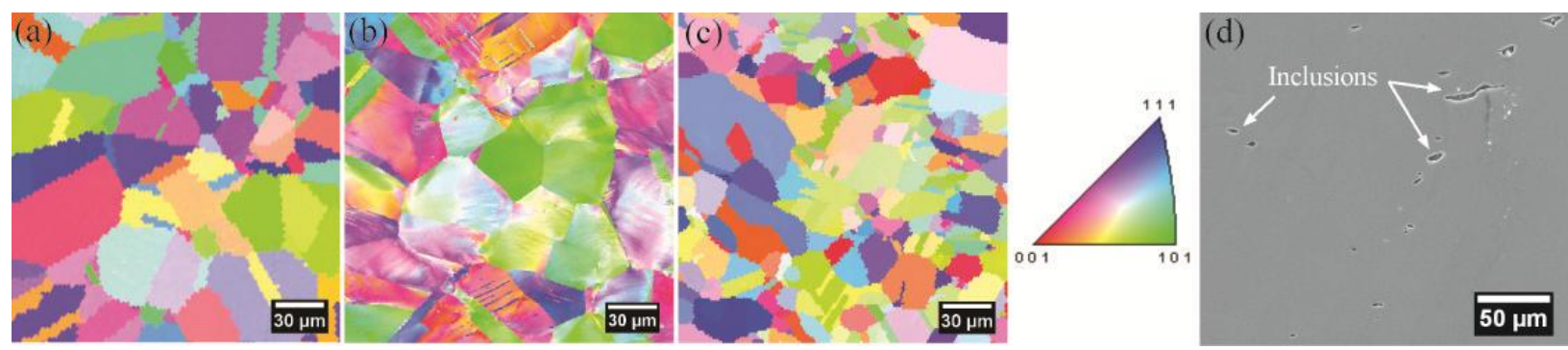

Fig. 1. Representative images of alloy microstructures for a) alloy AS (CP 304L), b) alloy ES (HP 304L), and c) alloy KS (HP 304L+Ni), and d) an SEM image showing alloy AS inclusions with several indicated by white arrows.

Table 2. Inclusions in alloys used in this study.

\begin{tabular}{cccc}
\hline \multicolumn{5}{c}{ No. Density, Avg. Size, } \\
Alloy & $\mathbf{m m}^{-2}$ & $\boldsymbol{\mu m}^{\mathbf{2}}$ & Type \\
\hline AS & $126 \pm 2$ & $16.1 \pm 7.9$ & MnS, Oxide \\
ES & $125 \pm 5$ & $3.4 \pm 1.5$ & Oxide \\
KS & $155 \pm 6$ & $3.5 \pm 1.6$ & Oxide \\
\hline
\end{tabular}

\subsection{Sample irradiation and preparation}

Samples were irradiated at $320^{\circ} \mathrm{C}$ in the BOR-60 liquid sodium fast reactor, at a neutron flux of $\sim 1.8 \times 10^{15} \mathrm{n} \cdot \mathrm{cm}^{-2} \cdot \mathrm{s}^{-1}(\mathrm{E}>0.1 \mathrm{MeV})$, corresponding to a damage rate of $9.4 \times 10^{-7} \mathrm{dpa} \cdot \mathrm{s}^{-1}(\mathrm{E}>0.1 \mathrm{MeV})$ calculated using the Norgett, Torrens and Robinson (NRT) model [20]. Previous comparisons have shown that BOR-60 irradiation creates very comparable defect structure in austenitic stainless steel as BWR irradiation [21]. 
After irradiation, four-point bend samples were made from the ends of tensile bars used in CERT tests [16] as shown schematically in Fig. 2. Samples were mechanically ground to a thickness of $\sim 800 \mu \mathrm{m}$ and electro-polished on one side to achieve a mirror finish for SCC testing. Final thickness variations were less than $10 \mu \mathrm{m}$. Parent tensile bar ID, bend sample ID, dose, and thickness are presented in Table 3. Additional details regarding four-point bend sample preparation are presented in refs. $[17,18]$.

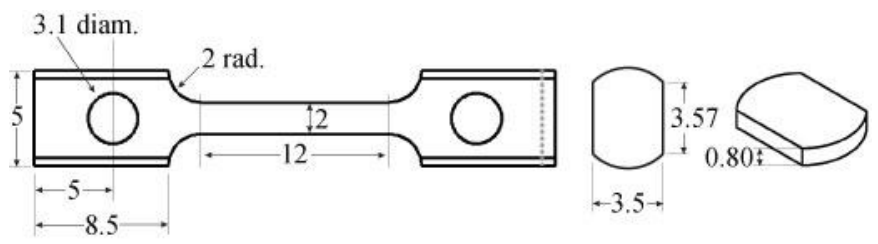

Fig. 2. Tensile bar geometry and approximate location of the cut made to create bend samples, whose final geometry is shown. Dimensions are in $\mathrm{mm}$.

Table 3. Neutron irradiated bend sample ID, dose, and thickness.

\begin{tabular}{|c|c|c|c|}
\hline $\begin{array}{l}\text { Parent Tensile } \\
\text { Sample ID }\end{array}$ & $\begin{array}{c}\text { Bend } \\
\text { Sample ID }\end{array}$ & $\begin{array}{c}\text { Dose, } \\
\text { dpa }\end{array}$ & $\begin{array}{c}\text { Thickness, } \\
\mu \mathrm{m}\end{array}$ \\
\hline AS14 & AS01 & 5.5 & 825 \\
\hline AS14 & AS02 & 5.5 & 797 \\
\hline AS14 & $\mathrm{AS} 03$ & 5.5 & 839 \\
\hline AS14 & AS04 & 5.5 & 801 \\
\hline AS19 & AS06 & 10.2 & 796 \\
\hline AS17 & AS07 & 10.2 & 791 \\
\hline AS19 & AS08 & 10.2 & 777 \\
\hline AS22 & AS09 & 47.5 & 807 \\
\hline AS23 & AS10 & 47.5 & 729 \\
\hline ES16 & ES01 & 10.2 & 770 \\
\hline ES21 & ES02 & 10.7 & 804 \\
\hline KS13 & KS01 & 9.6 & 806 \\
\hline KS13 & KS02 & 9.6 & 815 \\
\hline
\end{tabular}

\subsection{Four-point bend test procedure}

Fig. 3 shows a schematic of the loading fixture used for four-point bend tests. The fixture is oriented vertically (as shown in Fig. 3) inside the autoclave system described in ref. [16]. Load (monitored with a load cell in series with the fixture) is applied such that the loading point moves downward toward the sample support in Fig. 3b. Four-point bend test results focus on the convex bend surface (the convex surface is on the downward facing side of the sample), where crack initiation occurred. All figures will be presented with the sample oriented as shown in Fig. 3c, with the tensile stress-strain direction parallel to the longitudinal axis.

Finite element analysis (using Abaqus ${ }^{\mathrm{TM}}$ ) and a series of practice tests were performed on unirradiated, cold-worked 304L SS samples to determine stress-strain behavior at the surface of the bend sample, as 
described in refs. [17,18]. Deformation during practice tests was measured on the sample surface using digital image correlation techniques. Stress and strain at the bend sample surface were determined from measurements of applied load $\left(P_{b}\right)$ and sample bend deflection $\left(\delta_{b}\right)$ recorded during experimentation $[17,18]$.

Surface stress and strain measurements in the center $500 \mu \mathrm{m}$ of the sample (along the longitudinal axis, between the loading points) were not possible during SCC testing in the simulated LWR environment. Prior to macroscopic yield, effective stress on the bend surface (calculated according to the von Mises formulation) was uniform in the center region of the sample and increased linearly with applied load, as shown in Fig. 4a. Strain in this regime was calculated assuming Hooke's law and the modulus of SS at $300{ }^{\circ} \mathrm{C}, 166.3 \mathrm{GPa}$ [22]. Error in this relationship (represented by the dashed lines in Fig. 4a) was determined based on the observed variations in sample thickness provided in Table 3. After macroscopic yielding (noticeable by a deviation from linearity in the load vs. bend deflection curve), bend test results are represented in terms of plastic strain, which correlated with plastic bend deflection (total bend deflection less elastic bend deflection) as shown in Fig. 4b. Dashed lines in Fig. 4b represent error bounds on the strain measurement, determined by applying the error propagation method on the linear fit [18].

It should be noted that the stress-strain state on the four-point bend sample surface was not purely uniaxial. Effective stress was used because near the sample center the stress state had a positive $\sigma_{y y}$ component ( $\sim 30 \%$ of $\sigma_{x x}$ ) due to frictional constraint at the loading points. After macroscopic yield, the sample center was in a nearly pure state of uniaxial tensile strain $\left(\varepsilon_{x x}\right)$, but transverse $\left(\varepsilon_{y y}\right)$ strain near the sample edges approached $-40 \%$ of the applied $\varepsilon_{x x}$ due to geometric constraint.
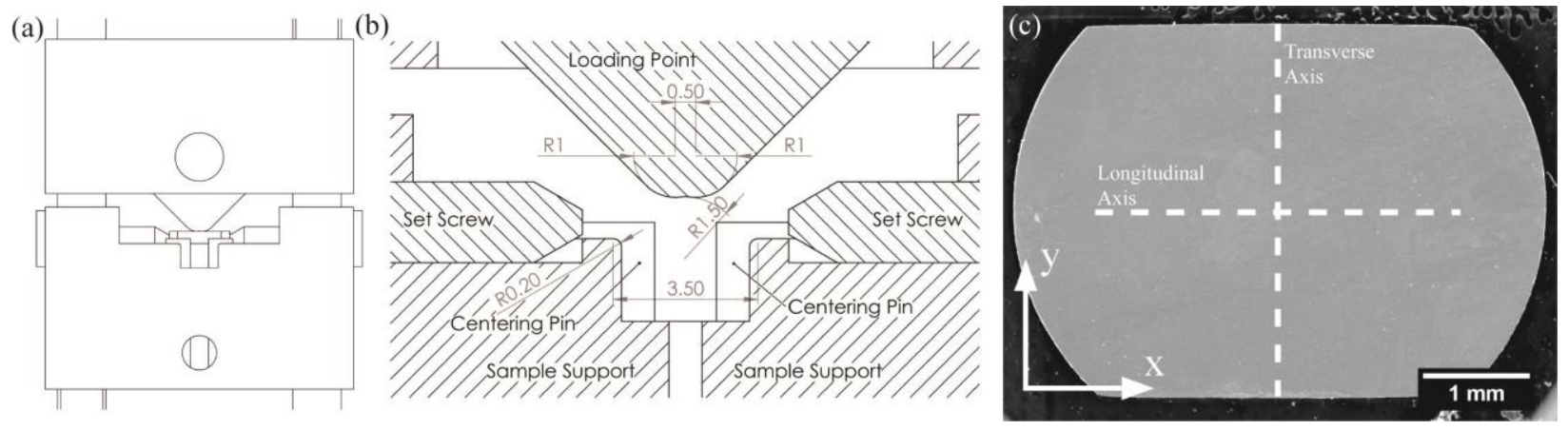

Fig. 3. a) Schematic (bend sample included) and b) cross-section view (bend sample excluded) of the four-point bend loading fixture. c) Sample orientation and coordinate system. 

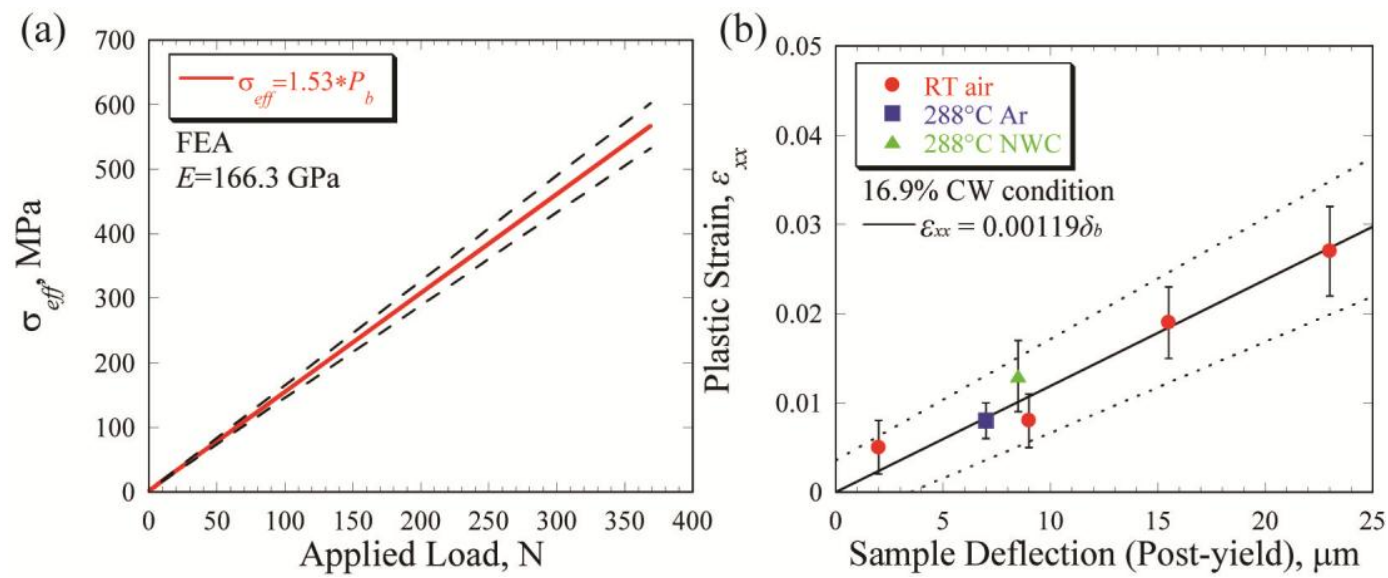

Fig. 4. a) Effective stress as a function of applied load in the elastic regime of the fourpoint bend test, and $b$ ) the correlation between plastic strain and sample deflection after macroscopic yield was achieved in the four-point bend test (from [17]).

Four-point bend tests were performed individually in the autoclave test system described in ref. [16], in either $288^{\circ} \mathrm{C}$ Ar gas or $288^{\circ} \mathrm{C}$ simulated normal water chemistry (NWC) conditions ( 2 ppm dissolved $\mathrm{O}_{2}$ and $0.2 \mu \mathrm{S} / \mathrm{cm}$ outlet conductivity via $\mathrm{H}_{2} \mathrm{SO}_{4}$ addition). It should be noted that dilute $\mathrm{H}_{2} \mathrm{SO}_{4}$ was added for the purpose of maintaining constant conductivity throughout each experiment, and does not represent inservice NWC conditions. A crosshead rate of $1.7 \times 10^{-8} \mathrm{in} \cdot \mathrm{s}^{-1}$ created a strain rate of $3.5 \times 10^{-7} \mathrm{~s}^{-1}$ at the surface of the bend sample, and each bend test lasted for approximately 24 hours. Additional details regarding environmental control as well as load and deflection measurement can be found in refs. [1618]. All tests were initially stopped at $\sim 40 \%-60 \%$ of the irradiated yield strength (as measured in $330{ }^{\circ} \mathrm{C}$ air), to characterize the sample surface. Additional stress increments were applied up to macroscopic yield, beyond which, small increments of strain were applied. The sample was removed after each step to perform microscopic examination of the sample surface for sites of crack initiation or dislocation channeling. No further tests were performed after the observation of crack initiation.

\subsection{Post-test characterization}

After each stress or strain increment, the sample surface was imaged in a JEOL JSM-6480 SEM. DCs were clearly visible in backscatter electron (BSE) images, and DC and slip transmission site density were quantified in the center $500 \mu \mathrm{m}$ of the sample along the transverse axis length. Slip transmission sites were characterized by a sharp directional change in the DC at a GB. DCs that did not transmit across a GB were termed 'discontinuous DCs.' After test completion, surface oxide from NWC exposure was removed from several samples to more clearly view locations of crack initiation following the procedure detailed in ref. [23]. XEDS was also used to characterize surface oxide composition on several samples. Finally, surface steps formed by DCs were analyzed on several samples, using replicas created from bend 
sample surfaces. Details regarding surface replication and analysis of the weighted average channel height are presented in ref. [23].

\section{Results}

\subsection{Stress corrosion cracking and localized deformation in $288{ }^{\circ} \mathrm{C} \mathrm{NWC}$}

\subsubsection{Stress corrosion cracking}

Results of four-point bend tests in $288^{\circ} \mathrm{C}$ NWC are summarized in Table 4, showing values of stress or strain after the bend test increment when DCs first formed (if prior to crack initiation) and before and after crack initiation was observed. For each sample, the stress for crack initiation was estimated as the midpoint of the stress increment during which crack initiation occurred. The magnitude of stress increments were chosen based on cracking behavior observed during CERT experiments [16] and prior bend test experiments, hence their variability. In the case of multiple measurements, the stress for crack initiation values were averaged to determine the average stress to initiate IASCC for a particular alloy and dose condition. Error on these averages was calculated using a technique described in [18], based on the magnitude of the test increment and error in stress measurement.

IASCC initiated prior to macroscopic yield in all alloy AS samples, and the average stress to initiate IASCC decreased with irradiation dose. Alloy ES was less susceptible to IASCC than alloy AS, as crack initiation on sample ES01 was not observed until after macroscopic yield (which occurred at a stress of $810 \mathrm{MPa}$ in the bend test). The initial crack likely originated at the sample edge, therefore additional strain was applied in an attempt to create a crack within the sample surface. Although the original crack did not propagate, a second large IG crack formed which also likely originated at the sample edge. Alloy KS exhibited no IG cracking in NWC, even after macroscopic yielding (which occurred at a stress of 755 $\mathrm{MPa}$ in the bend test) and the application of $\sim 10 \%$ plastic strain. 
Table 4. Results of four-point bend tests on CP 304L alloy AS samples in $288^{\circ} \mathrm{C} \mathrm{NWC}$.

\begin{tabular}{|c|c|c|c|c|c|c|c|c|}
\hline \multirow[b]{2}{*}{ Alloy } & \multirow[b]{2}{*}{$\begin{array}{c}\text { Dose, } \\
\text { dpa }\end{array}$} & \multirow[b]{2}{*}{$\begin{array}{c}\mathrm{YS} \text { in } 330^{\circ} \mathrm{C} \\
\text { air, } \mathrm{Mpa} \text { (from } \\
\text { ref. }[19])\end{array}$} & \multirow[b]{2}{*}{$\begin{array}{c}\text { Sample } \\
\text { ID }\end{array}$} & \multicolumn{3}{|c|}{ Effective stress $\left(\sigma_{\text {eff }}\right)$, MPa } & \multicolumn{2}{|c|}{ Average to initiate IASCC } \\
\hline & & & & $\begin{array}{c}\text { After increment } \\
\text { when DCs } \\
\text { first formed } \\
\end{array}$ & $\begin{array}{c}\text { Before increment } \\
\text { when cracking } \\
\text { initiated }\end{array}$ & $\begin{array}{c}\text { After increment } \\
\text { when cracking } \\
\text { initiated }\end{array}$ & $\begin{array}{l}\text { Stress }\left(\sigma_{e f f}\right), \\
\text { MPa }\end{array}$ & Strain $\left(\varepsilon_{x x}\right)$ \\
\hline \multirow{3}{*}{ AS } & \multirow{3}{*}{5.5} & \multirow{3}{*}{$783 \pm 11$} & AS01 & N/A & $630 \pm 39$ & $824 \pm 51$ & \multirow{3}{*}{$640 \pm 99$} & \multirow{3}{*}{$0.0038 \pm 0.0006$} \\
\hline & & & $\mathrm{AS} 02$ & $613 \pm 38$ & $613 \pm 38$ & $681 \pm 42^{\mathrm{a}}$ & & \\
\hline & & & AS04 & N/A & $\mathrm{N} / \mathrm{A}$ & $581 \pm 36$ & & \\
\hline \multirow{2}{*}{ AS } & \multirow{2}{*}{10.2} & \multirow{2}{*}{$824 \pm 5$} & AS06 & $\mathrm{N} / \mathrm{A}$ & $545 \pm 34$ & $613 \pm 38^{\mathrm{b}}$ & \multirow{2}{*}{$589 \pm 29$} & \multirow{2}{*}{$0.0035 \pm 0.0002$} \\
\hline & & & AS08 & $495 \pm 31$ & $613 \pm 38$ & $613 \pm 38$ & & \\
\hline \multirow{2}{*}{ AS } & \multirow{2}{*}{47.5} & \multirow{2}{*}{$906 \pm 5$} & AS09 & $441 \pm 27$ & $441 \pm 27$ & $501 \pm 31$ & \multirow{2}{*}{$454 \pm 32$} & \multirow{2}{*}{$0.0027 \pm 0.0002$} \\
\hline & & & AS10 & N/A & $430 \pm 27$ & $443 \pm 27^{\mathrm{a}}$ & & \\
\hline ES & 10.2 & $711 \pm 11$ & ES01 & $552 \pm 34$ & $790 \pm 49$ & $\varepsilon_{x x}=0.010 \pm 0.005^{\mathrm{cd}}$ & $\mathrm{N} / \mathrm{A}$ & $0.0074 \begin{array}{ll}+0.0033 \\
-0.0026\end{array}$ \\
\hline KS & 9.6 & $606 \pm 37$ & $\mathrm{KS} 02$ & $552 \pm 34$ & $\varepsilon_{x x}=0.094 \pm 0.006^{\mathrm{d}}$ & $\mathrm{N} / \mathrm{A}$ & & $\mathrm{N} / \mathrm{A}$ \\
\hline \multicolumn{9}{|c|}{ Two crack initiation sites observed. } \\
\hline
\end{tabular}

\subsubsection{Influence of surface inclusions}

Surface inclusions were analyzed on each four-point bend sample, as all 10 IG cracks in alloy AS intersected at least one surface inclusion. Table 5 reports the total number density of inclusions and the number of inclusions intersected by IG cracks on each sample. The crack on sample AS08 was within 10 $\mu \mathrm{m}$ of a surface inclusion, and likely intersected the inclusion sub-surface. Inclusions were not observed at crack initiation sites in alloy ES.

All IG crack initiation sites in alloy AS were unique in that the inclusions at these sites had an oxide cap, exemplified in Fig. 5a. Table 5 reports the number density of inclusions capped by oxide after NWC exposure. Not all bend sample surfaces were imaged in detail prior to crack initiation, but an oxide cap was observed at 4 of 5 cracking sites prior to initiation. Fig. $5 \mathrm{c}$ shows that after crack initiation, the oxide typically grew to cover the crack opening. Fig. 6 shows that oxides at these locations were rich in Mn.

Inclusion composition was analyzed on an unirradiated alloy AS sample before and after 24 hours of NWC exposure (a similar duration as a four-point bend test) in an un-stressed state. Oxide inclusions did not experience significant changes in appearance or composition, but MnS inclusions dissolved, displaying one of three different types of response: pit formation, Mn oxide formation within the inclusion site, or formation of a Mn oxide cap at the inclusion site, each exemplified in Fig. 7. Only one inclusion formed an oxide cap (Fig. 7d) similar to those at IASCC initiation sites, but the rarity of these 
sites was consistent with observations from irradiated samples, as shown in Table 5. The oxide cap was enriched in Mn (and had no concentration of Ti), confirming that the inclusion was formerly MnS.

As mentioned previously, alloy AS contained both MnS and oxide inclusions, while alloys ES and KS contained only oxide inclusions. Considering the size difference among $\mathrm{MnS}$ and oxide inclusions in alloy AS and the size distribution of inclusions in this alloy, it is estimated that $\sim 21$ of the $\sim 221$ inclusions in the uniform stress-strain region of the bend sample were MnS. Based on the number density of oxide occluded inclusions (shown in Table 5), only $20 \%$ of these MnS inclusions formed an oxide cap. No dissolved inclusions were observed on irradiated alloys ES and KS, likely because all inclusions were oxides, consistent with the response of oxide inclusions in alloy AS.

Table 5. The number density of inclusions observed on bend sample surfaces, inclusions which formed an oxide cap, and whether IG cracks intersected inclusions.

\begin{tabular}{ccccc}
\hline $\begin{array}{c}\text { Sample } \\
\text { ID }\end{array}$ & $\begin{array}{c}\text { Dose, } \\
\text { dpa }\end{array}$ & $\begin{array}{c}\text { No. density } \\
\text { inclusions, mm }\end{array}$ & $\begin{array}{c}\text { No. density inclusions with } \\
\text { oxide cap formation, } \mathbf{~ m m}^{-2}\end{array}$ & $\begin{array}{c}\text { No. cracks/No. crack- } \\
\text { inclusion intersections }\end{array}$ \\
\hline AS-Unirr & 0.0 & $82 \pm 4$ & $0.2 \pm 0.2$ & $0 / 0$ \\
AS01 & 5.5 & $145 \pm 6$ & $0.7 \pm 0.4$ & $1 / 2$ \\
AS02 & 5.5 & $129 \pm 5$ & $0.8 \pm 0.4$ & $2 / 2$ \\
AS03 & 5.5 & $129 \pm 6$ & $1.2 \pm 0.6$ & $0 / 0$ \\
AS04 & 5.5 & $143 \pm 6$ & $0.9 \pm 0.4$ & $1 / 1$ \\
AS06 & 10.2 & $95 \pm 5$ & $0.7 \pm 0.4$ & $2 / 3$ \\
AS07 & 10.2 & $107 \pm 5$ & $0.5 \pm 0.3$ & $0 / 0$ \\
AS08 & 10.2 & $133 \pm 7$ & $1.0 \pm 0.6$ & $1 / 1^{\mathrm{a}}$ \\
AS09 & 47.5 & $150 \pm 6$ & $0.9 \pm 0.4$ & $1 / 1$ \\
AS10 & 47.5 & $145 \pm 6$ & $1.5 \pm 0.6$ & $2 / 5$ \\
& & & & $2 / 0^{\mathrm{b}}$ \\
ES01 & 10.2 & $111 \pm 8$ & $0 \pm 0$ & $0 / 0$ \\
ES02 & 10.7 & $139 \pm 6$ & $0 \pm 0$ & $0 / 0$ \\
& & & & $0 / 0$ \\
KS01 & 9.6 & $143 \pm 6$ & $0 \pm 0$ & \\
KS02 & 9.6 & $167 \pm 10$ & $0 \pm 0$ & \\
\hline
\end{tabular}

anclusion within $10 \mu \mathrm{m}$, possible sub-surface intersection.

Inclusion intersections were not observed at the second crack initiation site, and the total was not measured due to crack length. 

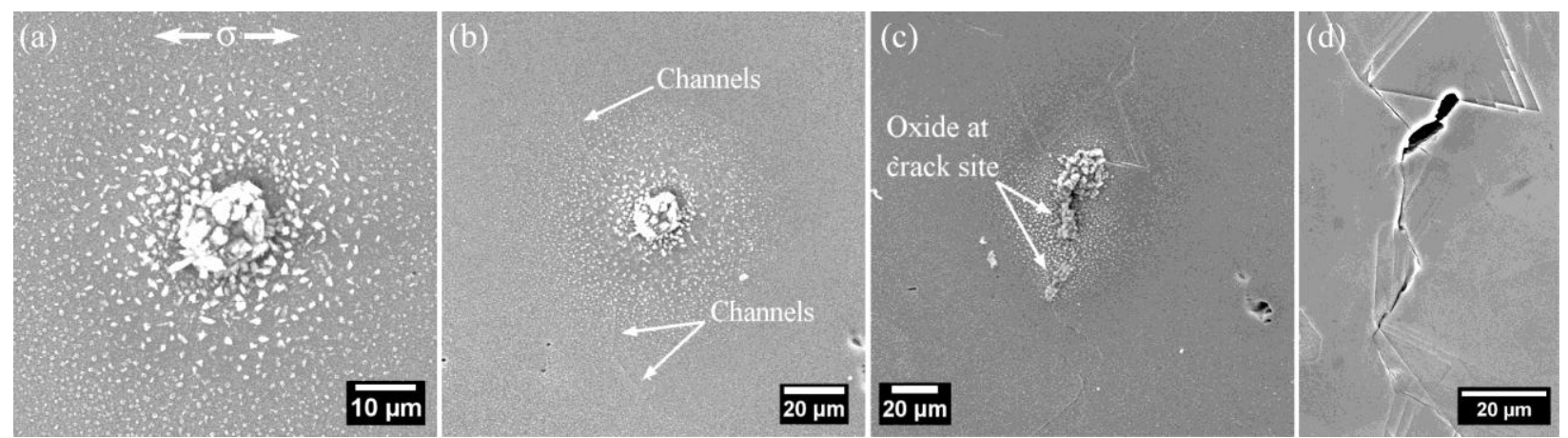

Fig. 5. Time progression of an IASCC initiation site in sample AS02, showing a) an oxide cap prior to cracking $\left(0.55 \sigma_{\mathrm{y}}\right)$, b) DC formation but no crack initiation at this site $\left.\left(0.61 \sigma_{\mathrm{y}}\right), \mathrm{c}\right) \mathrm{IG}$ crack initiation (the crack is obscured by corrosion product) $\left(0.68 \sigma_{\mathrm{y}}\right)$, and $d)$ the inclusion and crack site after oxide removal $\left(0.68 \sigma_{y}\right)$.

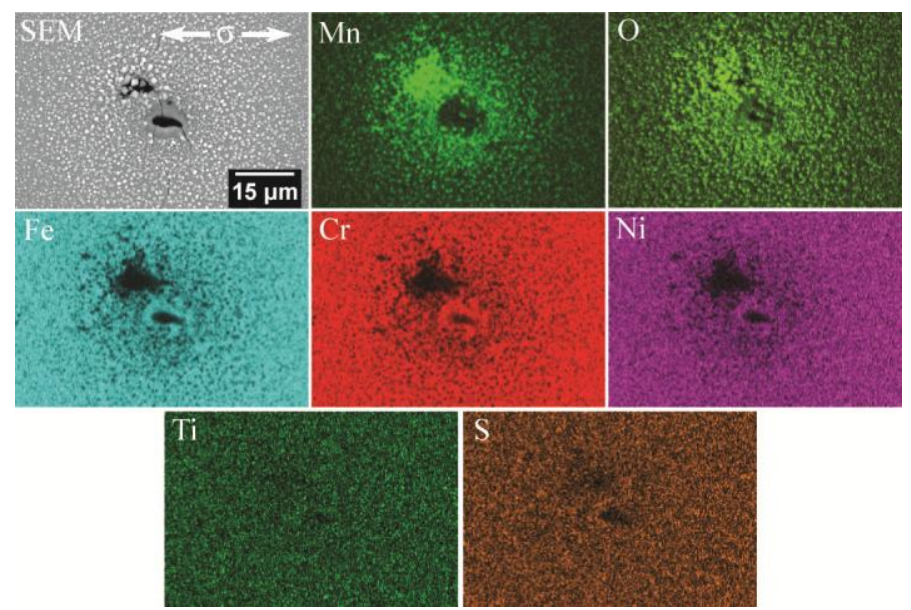

Fig. 6. Chemical maps of an oxide cap near a site of IASCC initiation on 47.5 dpa sample AS10.
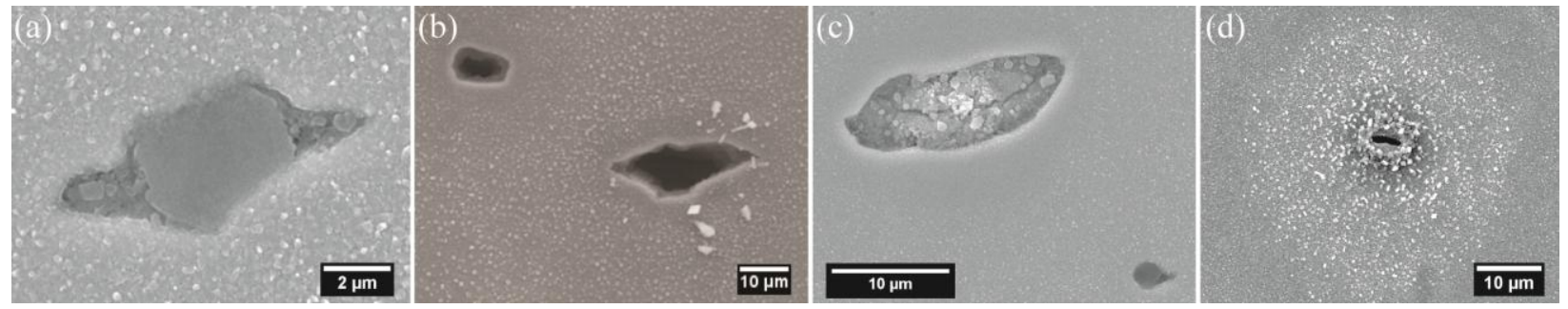

Fig. 7. Different inclusion responses to NWC exposure on the unirradiated alloy AS sample: a) an oxide inclusion that was relatively unchanged by NWC exposure, b) MnS which formed pits, c) MnS which formed Mn oxide within the inclusion site, and d) MnS which formed a Mn oxide cap. 


\subsubsection{Localized deformation}

Dislocation channels were observed on all irradiated samples and conditions in the four-point bend test after the application of very small stresses. In several cases, DCs were observed after the application of a stress as low as $\sim 50 \%$ the macroscopic yield strength, as shown in Table 4. Removing surface oxidation from alloy AS samples revealed that 5 of 6 initiation sites had discontinuous DCs intersecting the inclusion at locations where the oxide cap had formed, exemplified in Fig. 8. Despite this observation, DCs were only observed on 3 of 7 samples before crack initiation: AS02 (18 DCs), AS08 (72 DCs), and AS09 (4 DCs). It is also notable that there were no intersecting DCs at sites ( 7 of 7 sites) with oxide caps that produced no IG crack initiation, Fig. 9.

Table 6 summarizes DC measurements on alloys ES and KS after similar levels of applied strain in NWC. Similar to alloy AS samples, DCs were observed well before macroscopic yield. The number density of channels and slip transmission sites increased rapidly with strain until yield, after which the rate of channel and transmission site formation decreased. Channel density was similar for both HP alloys, but the density of slip transmission sites was greater in alloy KS at all strains.
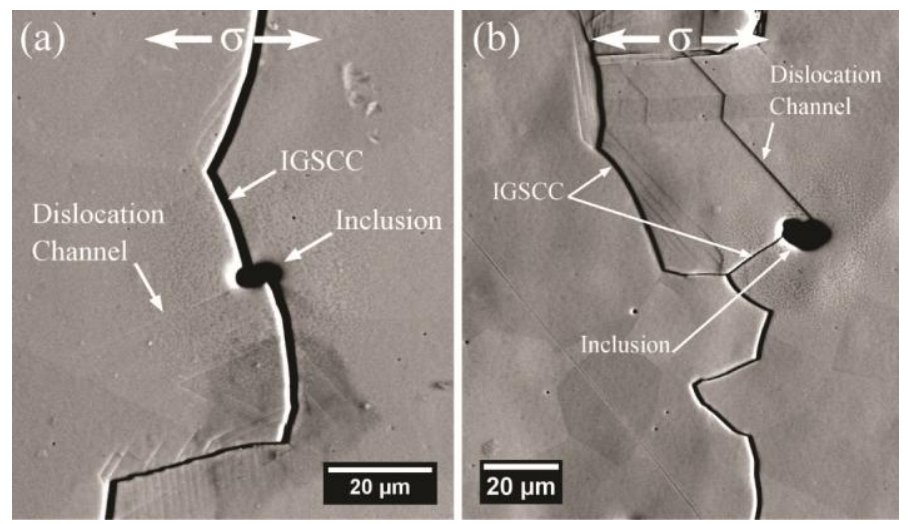

Fig. 8. IG crack initiation sites on samples a) AS01 and b) AS09 after oxide removal. Discontinuous DCs intersecting inclusions are indicated.
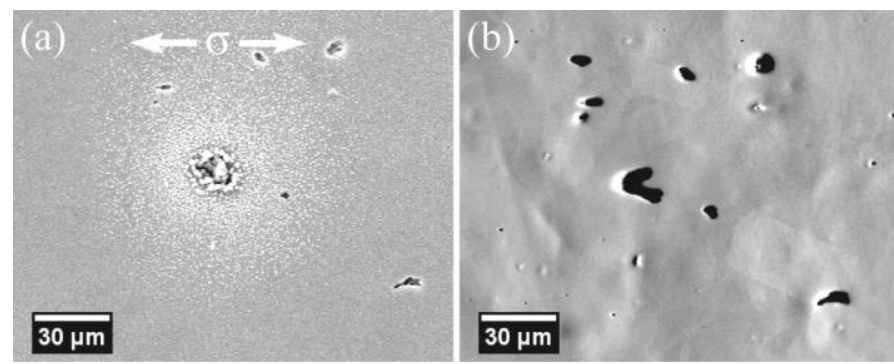

Fig. 9. An inclusion with an oxide cap but no adjacent IG cracking on sample AS09 a) before and b) after oxide removal. 
Table 6. Dislocation channel analysis on samples strained in $288^{\circ} \mathrm{C} \mathrm{NWC}$ and $288^{\circ} \mathrm{C}$ Ar.

\begin{tabular}{|c|c|c|c|c|c|c|c|c|c|c|}
\hline Alloy & $\begin{array}{c}\text { Dose, } \\
\text { dpa }\end{array}$ & $\begin{array}{c}\text { Sample } \\
\text { ID }\end{array}$ & $\sigma_{\text {eff }}, \mathrm{MPa}$ & Strain & Environment & $\begin{array}{c}\text { Channels, } \\
\mathrm{mm}^{-2}\end{array}$ & $\begin{array}{c}\text { Slip transmissions, } \\
\mathrm{mm}^{-2} \\
\end{array}$ & $\begin{array}{c}\text { Trans mission Sites } \\
\text { per Channel }\end{array}$ & $\begin{array}{l}\text { Channel-Inclusion } \\
\text { Intersections, } \mathrm{mm}^{-2}\end{array}$ & $\begin{array}{c}\text { Weighted Ave rage } \\
\text { Channel Height, nm }\end{array}$ \\
\hline AS & 5.5 & AS03 & 664 & $0.40 \%$ & $288^{\circ} \mathrm{C} \mathrm{Ar}$ & $68 \pm 6$ & $16 \pm 3$ & $0.24 \pm 0.07$ & $5 \pm 2$ & $\begin{array}{rr}55 & +15 \\
& -12 \\
\end{array}$ \\
\hline \multirow[t]{2}{*}{ AS } & \multirow[t]{2}{*}{10.2} & \multirow[t]{2}{*}{ AS07 } & 714 & $0.43 \%$ & \multirow[t]{2}{*}{$288^{\circ} \mathrm{C} \mathrm{Ar}$} & $279 \pm 13$ & $81 \pm 7$ & $0.29 \pm 0.04$ & $11 \pm 3$ & $58 \begin{array}{r}+15 \\
-13\end{array}$ \\
\hline & & & 952 & $0.57 \%$ & & $1287 \pm 44$ & $478 \pm 27$ & $0.37 \pm 0.03$ & $21 \pm 6$ & NM \\
\hline \multirow{5}{*}{ ES } & \multirow{5}{*}{$\sim 10$} & ES02 & 523 & $0.31 \%$ & $288^{\circ} \mathrm{C} \mathrm{Ar}$ & $81 \pm 7$ & $19 \pm 3$ & $0.23 \pm 0.06$ & $2 \pm 1$ & NM \\
\hline & & ES01 & 552 & $0.33 \%$ & NWC & $184 \pm 11$ & $40 \pm 5$ & $0.22 \pm 0.04$ & NM & NM \\
\hline & & ES02 & 729 & $0.44 \%$ & $288^{\circ} \mathrm{C} \mathrm{Ar}$ & $505 \pm 17$ & $139 \pm 9$ & $0.28 \pm 0.03$ & $12 \pm 3$ & $70 \begin{array}{l}+13 \\
-12\end{array}$ \\
\hline & & ES01 & 790 & $0.47 \%$ & NWC & $788 \pm 21$ & $286 \pm 13$ & $0.36 \pm 0.03$ & NM & NM \\
\hline & & ES01 & $\mathrm{N} / \mathrm{A}$ & $2.29 \%$ & NWC & $3262 \pm 81$ & $1610 \pm 57$ & $0.49 \pm 0.03$ & NM & NM \\
\hline \multirow{5}{*}{ KS } & \multirow{5}{*}{9.6} & KS01 & 489 & $0.29 \%$ & $288^{\circ} \mathrm{C} \mathrm{Ar}$ & $48 \pm 6$ & $23 \pm 4$ & $0.47 \pm 0.13$ & $3 \pm 1$ & NM \\
\hline & & KS02 & 552 & $0.33 \%$ & NWC & $132 \pm 9$ & $54 \pm 6$ & $0.41 \pm 0.07$ & NM & $\mathrm{NM}$ \\
\hline & & KS01 & 680 & $0.41 \%$ & $288^{\circ} \mathrm{C} \mathrm{Ar}$ & $564 \pm 31$ & $243 \pm 20$ & $0.43 \pm 0.06$ & $8 \pm 3$ & $\begin{array}{ll} & +17 \\
& +15\end{array}$ \\
\hline & & KS02 & 743 & $0.45 \%$ & NWC & $868 \pm 31$ & $417 \pm 21$ & $0.48 \pm 0.04$ & NM & NM \\
\hline & & $\mathrm{KS} 02$ & N/A & $2.35 \%$ & NWC & $3477 \pm 107$ & $1980 \pm 81$ & $0.57 \pm 0.04$ & $\mathrm{NM}$ & $\mathrm{NM}$ \\
\hline
\end{tabular}

NM indicates that value was not measured, N/A indicates that value was not available.

\subsection{Localized deformation in $288{ }^{\circ} \mathrm{C} \mathrm{Ar}$}

Four-point bend tests in $288^{\circ} \mathrm{C}$ Ar were performed to more accurately measure DC formation, as no cracking or surface oxidation occurred in this environment. DC measurements from these experiments are also shown in Table 6. After $\sim 0.3 \%$ strain, DC density was similar in alloys ES and KS, lower in alloy AS at $10.2 \mathrm{dpa}$, and lowest in alloy AS at $5.5 \mathrm{dpa}$. Alloy KS had the highest density of slip transmission sites. DC step height was also measured on each condition after $\sim 0.3 \%$ strain, showing that HP alloys formed larger steps than alloy AS at 5.5 or $10.2 \mathrm{dpa}$, although the differences were very small.

The number of DCs intersecting surface inclusions was also quantified on samples strained in Ar, to observe whether inclusions caused DC formation. The number density of these intersections was low with respect to both the total number of inclusions or DCs, and did not scale with DC density as more strain was applied. Inclusions with intersecting DCs were imaged in detail to determine whether those with adjacent inclusions had formed internal cracks or debonded from the matrix, but internal inclusion cracks were only observed on sample AS07 after the application of $0.57 \varepsilon_{\mathrm{xx}}$.

After straining in $288^{\circ} \mathrm{C} \mathrm{Ar}$, samples AS03 and AS07 were exposed to NWC in an un-stressed state for 24 hours to determine whether inclusion corrosion was affected by prior deformation. The number density of surface inclusions that formed an oxide cap (reported in Table 5) was similar to that on samples strained in NWC without pre-straining in Ar. 


\section{Discussion}

The capability to characterize IASCC initiation sites provided new information on the IASCC initiation behavior of stainless steel. Observations presented in the Results section can be summarized as follows:

- Alloy AS initiated IG cracks at applied stresses that were well below the macroscopic yield stress, and the stress to initiate IASCC decreased with increasing irradiation dose.

- $\mathrm{MnS}$ inclusions enhanced susceptibility to IASCC initiation in alloy AS.

- Discontinuous DCs intersecting surface inclusions were often observed at IASCC initiation sites in alloy AS, although only few DCs were observed prior to crack initiation on this alloy.

- Alloy ES displayed a significant network of DCs prior to crack initiation, and cracking likely did not occur until after macroscopic yield.

- Alloy KS had the highest number of slip transmission sites and exhibited no cracking susceptibility.

The following discussion will first compare cracking behavior in CERT and four-point bend tests and then address major observations in more detail.

\subsection{The stress dependence of IASCC initiation}

The average stress required for crack initiation decreased with irradiation dose in CP 304L alloy AS. This observation was interesting, considering that the hardness of this alloy increased over the same dose range [16]. Interval censored data analysis [24,25] was applied to determine whether differences in stress required to initiate IASCC among dose conditions were statistically significant. The interval censored analysis technique was appropriate for comparing data from the four-point bend tests, because the stress interval during which IASCC initiation occurred was known, with bounds as the maximum stress applied prior to crack initiation and the stress applied that resulted in crack formation (presented in Table 4). This allowed the construction of Kaplan-Meier survival curves for each irradiation dose condition, which were then compared using the log-rank hypothesis test. It is important to note that this comparison technique is non-parametric, and does not assume the data follows any particular distribution type. This is appropriate considering the small test population from each condition.

5.5 and 10.2 dpa alloy AS conditions were compared first, resulting in a low (45\%) probability that a significant difference existed in the stress required for IASCC initiation. The low confidence in this case was likely due to a combination of the limited dataset and the small difference in irradiation exposure. Because of their similarity, 5.5 and 10.2 dpa conditions were compared together against the $47.5 \mathrm{dpa}$ condition. This comparison determined that the stress required for IASCC initiation was lower in the 47.5 
dpa condition, with greater than $90 \%$ confidence. Both the decrease in stress necessary for IASCC initiation with irradiation dose and the magnitude of the stress threshold ( $50 \%$ of the irradiated yield strength) observed in this study were consistent with previous observations from uniaxial CLT [15] and O-ring CLT [9,26], despite differences in experiment type, test environment, and material condition.

Recent work analyzing DCs and cracking behavior in proton-irradiated SS has shown a strong dependence on the interaction between DCs and GBs [6,7]. Therefore, DC behavior was considered as a cause for the observed decrease in stress to initiate IASCC with dose. In proton irradiated SS [5,7,27-29], crack initiation is not typically observed with the appearance of the first DC, but observations of DC behavior in the highly IASCC-susceptible neutron-irradiated alloy AS indicate that this was a possibility due to the limited number of DCs observed prior to crack initiation.

Few DCs were observed prior to IASCC initiation, yet discontinuous DCs were observed at all but one IASCC initiation site in alloy AS. Therefore, the stress dependence of DC initiation can explain the decrease in stress for IASCC initiation with dose. DCs form with increasing stress, making it possible to back extrapolate the stress to initiate DCs on each sample, based on DC density measurement after the application of a certain amount of stress. DC density increased linearly with stress in the elastic strain region for $\sim 10$ dpa conditions ( $3.4 \pm 1.0$ channels per $\mathrm{mm}^{2}$ per MPa), as shown in Fig. 10a. Fig. 10b shows that at each irradiation dose condition in alloy AS, the average stress to initiate DCs was less than the average stress for IASCC initiation. Error on the average stress to initiate DCs was based on the fit of the correlation in Fig. 10a, error in the stress measurement, and error in the number of DCs observed [18].

To improve confidence in the observation that the stress required for DC initiation decreased with dose, irradiated microstructures (TEM analysis was performed on alloy AS in refs. [30-32]) were considered, as microstructure controls hardening and thus deformation in irradiated SS. The size distribution of dislocation loops shifts to slightly larger sizes as dose increases [32], with a subsequent decrease in dislocation loop density [30-32]. As irradiation dose progresses past $\sim 10 \mathrm{dpa}$, dislocation loops begin to dissociate and form SFT [31]. Irradiation-induced formation of G-phase precipitates is apparent at $\sim 5 \mathrm{dpa}$, and the number density of precipitates increases with irradiation dose [31,32].

Irradiated microstructure observations explain the increase in hardness with irradiation dose in alloy AS [16], because precipitates are stronger obstacles to dislocation movement than dislocation loops [33,34]. However, there is no obvious explanation for why the stress to initiate DCs decreased with dose. Jiao and Was [35] showed that dislocation loop density correlated with weighted average DC height, indicating that deformation became more localized as density increased. Therefore, it is possible that the stress for DC formation was affected by the decreasing loop density as a function of dose, although this 
interpretation is contrary to the expectation that localized deformation requires more stress to initiate in harder materials.

In summary, DCs were observed before crack initiation and at most IASCC initiation sites following crack initiation. It was also observed that the stress to initiate DCs was less than the stress to initiate IASCC at each irradiation dose in alloy AS. Therefore, it is likely that discontinuous DCs control the stress dependence of IASCC initiation.
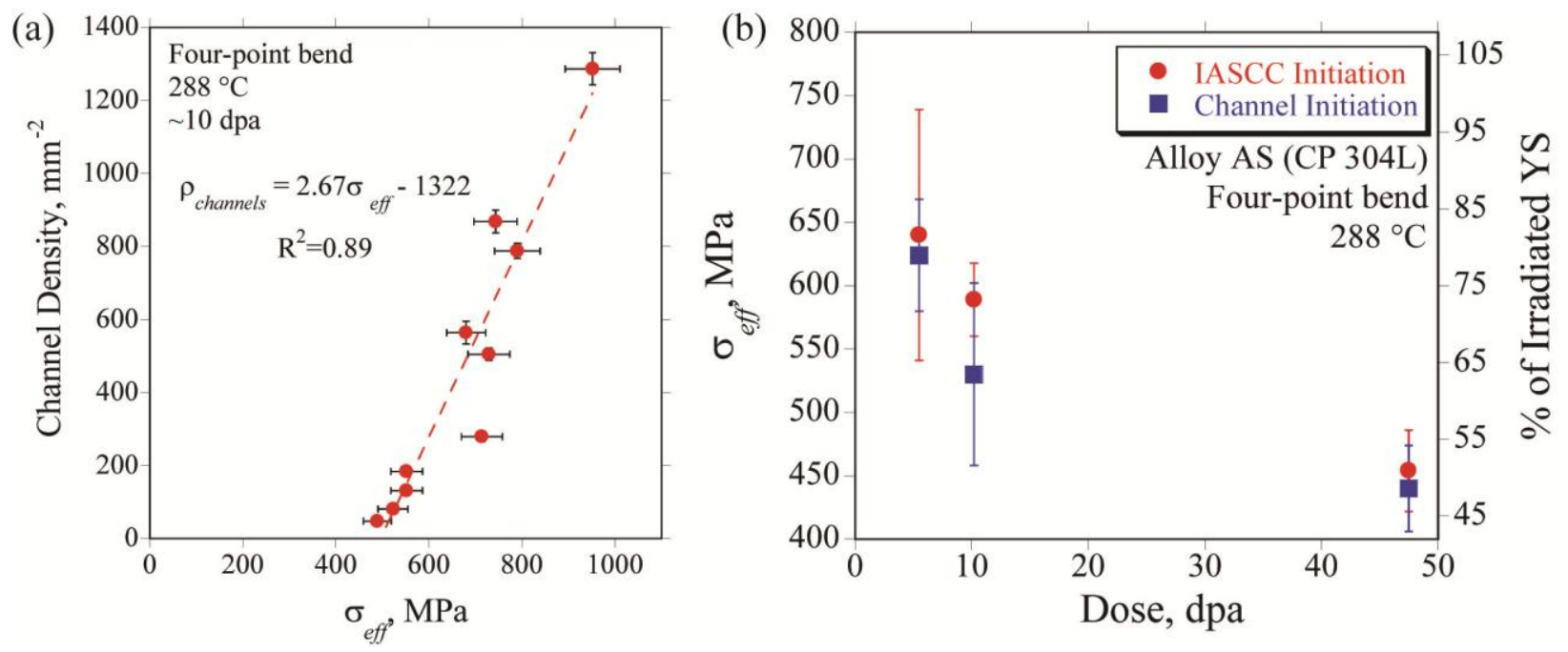

Fig. 10. a) Stress dependence of channel density for $\sim 10$ dpa irradiated conditions during elastic deformation and $\mathrm{b}$ ) average stress (and approximate $\%$ of the irradiated yield stress on the right vertical axis) to initiate DCs and initiate IASCC in alloy AS as a function of irradiation dose.

\subsection{The role of MnS inclusions in IASCC initiation}

All IG cracks in alloy AS originated at MnS inclusions, indicating that they participated in the IASCC initiation process. These inclusions were confirmed to be $\mathrm{MnS}$, as only $\mathrm{MnS}$ inclusions dissolved in NWC and resulted in oxide cap formation. Although MnS inclusions cause SCC initiation in unirradiated pressure vessel steels [36,37], cracking in unirradiated steel was transgranular, while IASCC is intergranular. Furthermore, in proton-irradiated alloy AS tested in NWC by Busby [38], many cracks were observed in the irradiated portion of the sample, but no cracks were reported outside the irradiated area. These observations show that IASCC at MnS inclusions is caused by a different mechanism than SCC at MnS inclusions in unirradiated steels.

The low stress required for IASCC initiation in alloy AS and the large size of MnS inclusions (relative to oxide inclusions in this alloy) led to the expectation that surface inclusions are stress concentrators, leading to crack initiation. However, stress concentration at inclusions cannot be the controlling factor of 
IASCC initiation as inclusions were similar at all dose conditions and therefore cannot explain the decreasing stress to cause IASCC initiation with irradiation dose. The limited observation of DCs prior to crack initiation and the coincidence of DCs at 5 of 6 IASCC initiation sites indicate that these DCs were caused by stress concentration at the inclusion site. To ensure this was the case, the probability of a DC randomly forming in a grain also adjacent to a $\mathrm{MnS}$ inclusion was calculated and compared to the observed frequency of DCs at IASCC initiation sites. The probability that a DC forms in the uniform stress-strain region of the bend sample adjacent to a $\mathrm{MnS}$ inclusion is $\sim 0.01 \%$, calculated by multiplying the probabilities that one of the $\sim 2200$ grains in the center of the bend sample possesses a DC (72 was the maximum number observed prior to cracking) as well as a MnS inclusion ( 63 grains are adjacent a MnS inclusion). This calculated probability is much lower than the observed frequency of DCs at IASCC initiation sites (83\%), therefore, DCs at MnS inclusions associated with IG cracks formed preferentially as a result of stress concentration at the inclusion. It is possible that stress concentration at these sites was caused by the crack after its initiation, but considering that all inclusions with a similar appearance as those at IASCC initiation sites (those with oxide cap formation) did not have adjacent DCs and were not associated with cracking, it is likely that DCs at IASCC initiation sites were a factor in the crack initiation process and therefore formed prior to crack initiation.

Considering independent observations of pitting at sulfide inclusions which enhanced SCC susceptibility $[39,40]$ and the observation of oxide cap formation at all IASCC initiation sites in alloy AS, the response of $\mathrm{MnS}$ inclusions to NWC exposure was examined more closely. Analysis of the $\mathrm{Mn} / \mathrm{S} / \mathrm{H}_{2} \mathrm{O}$ Pourbaix diagram at $288^{\circ} \mathrm{C}$ (Fig. 11, adapted from the Pourbaix diagram at $250{ }^{\circ} \mathrm{C}$ published by Zhou et al. [41]) shows that in NWC conditions ( $200 \mathrm{mV}_{\mathrm{SHE}}$ and $\mathrm{pH} \sim 5.65$ [42]), $\mathrm{MnS}$ will dissolve to form $\mathrm{SO}_{4}{ }^{2-}$ and $\mathrm{Mn}_{2} \mathrm{O}_{3}$. IASCC occurred only at MnS inclusions with an oxide cap. Therefore, it is likely that oxide cap formation created a preferential site for IASCC initiation. It remains unknown why only $\sim 20 \%$ of $\mathrm{MnS}$ inclusions resulted in oxide cap formation, although local water flow and inclusion geometry were likely influencing factors.

When a dissolving MnS inclusion is occluded by oxide cap formation, a crevice condition is formed. Within the crevice, deaeration of water due to oxide formation causes local acidification as well as the formation of a potential gradient between the crevice depth and the crevice mouth [43]. This potential gradient and the presence of a high sulfate $\left(\mathrm{SO}_{4}{ }^{2-}\right)$ ion concentration (in localized areas near $\mathrm{MnS}$ inclusions due to their dissolution) attract these anions into the crevice, increasing the local conductivity. It is well established from CGR tests that increased conductivity enhances crack growth rate [44,45], and crack initiation is enhanced with increased sulfate concentration [46,47]. Although $\mathrm{H}_{2} \mathrm{SO}_{4}$ was added to the feedwater during testing to control conductivity and it is known that even very low concentrations 
( 100 ppb) of sulfate increase IG cracking susceptibility in austenitic SS [47], cracking only initiated at $\mathrm{MnS}$ inclusions in alloy AS. Considering the availability of sulfur at $\mathrm{MnS}$ sites (based on their average size), it is evident that dissolving $\mathrm{MnS}$ created a more aggressive environment than the ppb levels of $\mathrm{H}_{2} \mathrm{SO}_{4}$ added to control conductivity.

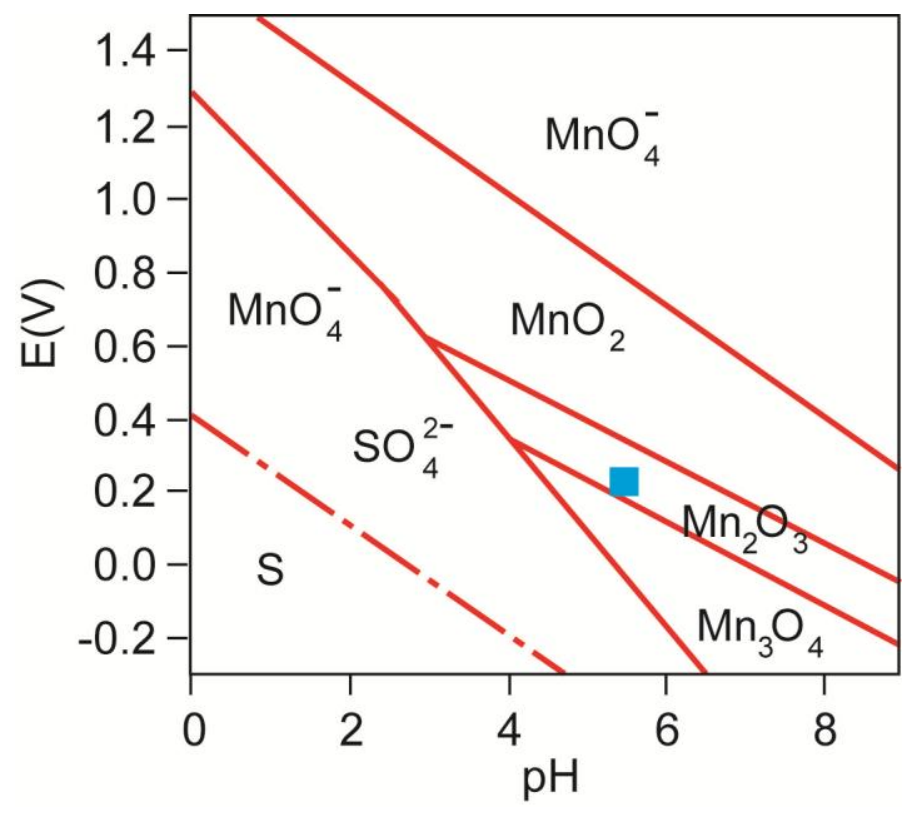

Fig. 11. The Pourbaix diagram for the $\mathrm{Mn} / \mathrm{S} / \mathrm{H}_{2} \mathrm{O}$ system at $288^{\circ} \mathrm{C}$ (adapted from the diagram published by Zhou et al. [41]), indicating stability of $\mathrm{SO}_{4}{ }^{2-}$ and $\mathrm{Mn}_{2} \mathrm{O}_{3}$ in $\mathrm{NWC}$ conditions (the location of the blue square). The ppb levels of $\mathrm{H}_{2} \mathrm{SO}_{4}$ added to control conductivity during the bend tests are expected to have negligible effect on $\mathrm{pH}$ [47].

Although literature regarding the effect of MnS inclusions on IASCC is limited, Jiao et al. [48] found IG cracks adjacent to $\mathrm{MnS}$ inclusions intersected by DCs, which led to the assumption that internal cracks within inclusions caused GB cracking, similar to what is observed in Ni-base alloys [49,50]. DCs appear to have caused internal cracks within inclusions during experiments in $288^{\circ} \mathrm{C}$ Ar in both Jiao's work [48] and in four-point bend tests; however, this type of cracking was only observed after an applied stress much larger than that necessary to cause IASCC initiation in NWC. Furthermore, the alloy AS sample with cracked inclusions did not display an increased density of oxide capped inclusion sites after exposure to NWC in an un-stressed condition. Therefore, cracking within inclusions did not promote oxide cap formation, an apparent precursor for IASCC initiation in alloy AS.

This comparison also illustrates that IG crack initiation at MnS inclusions is caused by a different mechanism than that at oxide inclusions [51]. Cracking of oxide inclusions forms a crevice condition similar to that at oxide capped $\mathrm{MnS}$ inclusions, but more than $1.1 \%$ plastic strain was necessary to crack 
oxide inclusions and create this condition in proton irradiated SS [51], compared to a maximum of $0.38 \%$ total strain required to cause IG crack initiation in alloy AS.

MnS inclusions clearly enhance IASCC susceptibility in alloy AS. MnS dissolves after exposure to NWC, forming a locally aggressive environment with a high potential for IASCC initiation, and acting as a stress concentrator that induces DC formation. Based on these observations and information from the literature, a mechanism for IASCC initiation in the CP 304L alloy AS is proposed.

\subsection{The IASCC mechanism in CP 304L alloy AS}

A locally aggressive environmental condition, caused by MnS dissolution and occlusion of the site by formation of an oxide cap, greatly enhances susceptibility of CP 304 SS to IASCC initiation. Deaeration of the water under the cap causes local acidification and the formation of a potential gradient between the tip and the mouth of the crevice [43]. The potential gradient and a high sulfate $\left(\mathrm{SO}_{4}{ }^{2-}\right)$ ion concentration (due to MnS dissolution) attract sulfate anions into the crevice, increasing local conductivity. Enhanced conductivity and sulfate concentration in LWR environments have both been shown to enhance crack growth and initiation.

In addition to the locally aggressive environment, local stress amplification at this site is required for IG cracks to initiate. The observation of DCs at oxide-capped MnS inclusion sites associated with IG cracks (and the lack of DCs at oxide-capped MnS inclusions not associated with IG cracks) strongly suggest that the formation of dislocation channels is a necessary condition for IASCC initiation. Therefore, it is probable that the superposition of stresses caused by 1) the dissolved inclusion and 2) a favorably oriented GB led to the formation of the DC, which then further amplified the local stress at the GB intersecting this inclusion site. In the presence of the aggressive environment, this stress concentration at the GB resulted in crack initiation as represented schematically in Fig. 12. The only exception to this situation (one case in which a DC was not observed intersecting the inclusion where IASCC initiated) the stress concentration necessary for IASCC initiation was likely achieved as a result of a triple point near the inclusion. Kamaya et al. [52] has shown that microstructural features such as this cause local stress concentration. 

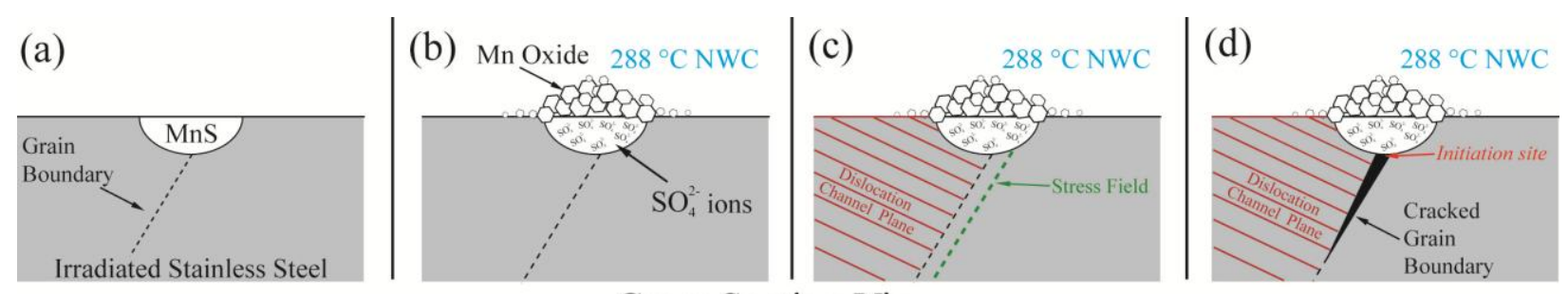

Cross Section View

(a)

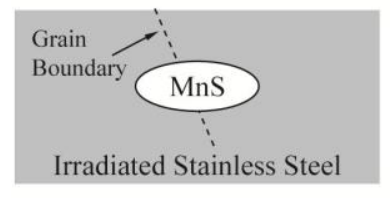

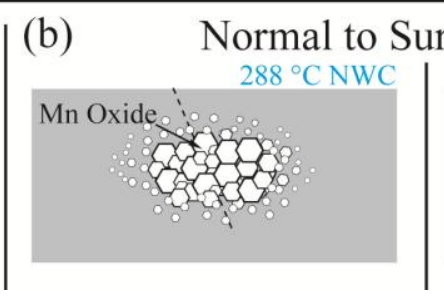

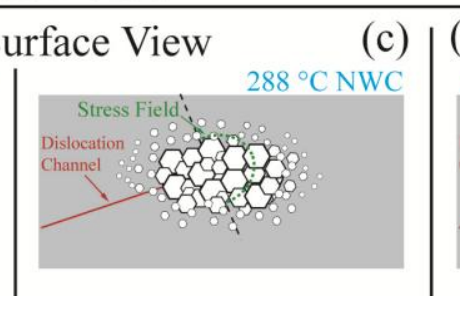

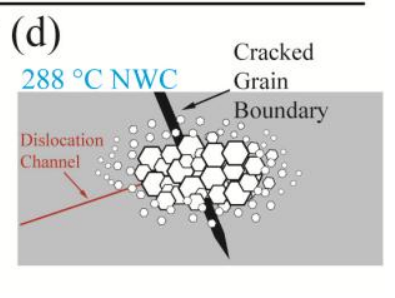

Fig. 12. IASCC initiation caused by a dissolving MnS inclusion and a stress field formed by a discontinuous DC intersecting the incident GB. a) A MnS inclusion at a grain boundary prior to exposure, b) after exposure to NWC, the MnS oxide dissolves to form an oxide cap which occludes the inclusion site and attracts $\mathrm{SO}_{4}{ }^{2-}, \mathrm{c}$ ) a discontinuous dislocation channel intersects the grain boundary at the inclusion site, creating a field of high stress, and d) IASCC initiates at this site.

The decrease in stress to initiate IASCC with increasing irradiation dose suggests that DCs at crack initiation sites formed at lower stress in higher dose material. However, support for this assertion is not obvious when considering available irradiated microstructure data. Uniaxial CLT [15], four-point bend, and O-ring CLT $[9,26]$ results all indicate a threshold stress to cause IASCC initiation at $\sim 50 \%$ of the irradiated yield strength after sufficient irradiation damage. However, less irradiation dose achieved this threshold in more aggressive environments, implying that environment interaction with GBs is an important factor (dislocation channeling is independent of corrosion potential). It is possible that changes in GB composition with increasing dose may enhance GB cracking sensitivity, consistent with observations that $\Sigma 3$ coincident site lattice boundaries are less prone to RIS [53] and IASCC [5] than random high angle (RHA) boundaries.

GB compositions for the alloys used in this study were analyzed quantitatively using STEM-EDS by Field et al. [53,54], showing that RIS increased with irradiation dose in alloy AS. GB Cr depletion has been shown to control IG cracking susceptibility [55], but evidently does not control IASCC because alloy KS (which had no cracking susceptibility) had the lowest GB Cr concentration of the alloys used in this study. Alternatively, Si segregation increased in alloy AS with dose [53], a factor which enhances IG corrosion in irradiated SS $[11,56]$. The acidic environment formed within a dissolving $\mathrm{MnS}$ crevice was likely analogous to the acidic environment used by Fukuya et al. [11] and exacerbated corrosive attack at 
the GB intersecting this site. As Si enrichment increased with irradiation dose, IG corrosion was likely enhanced and the stress necessary for IASCC reduced.

Four-point bend tests create a clear picture of the IASCC mechanism in alloy AS. A locally aggressive environment is formed due to the dissolution of MnS inclusions. At all locations where IG cracks initiated, an oxide cap was formed, occluding the inclusion site and creating a crevice condition with a deaerated and acidified environment within the crevice. A high sulfate ion concentration and solution conductivity created a favorable condition for crack initiation, but local stress concentration was required for cracking to occur. Stress concentration at a favorably oriented GB intersecting the dissolved $\mathrm{MnS}$ inclusion site caused the formation of a discontinuous DC, which further increased stress concentration at the GB and caused IASCC initiation.

\subsection{Dislocation channeling and IASCC in HP alloys ES and KS}

Additional analysis was necessary to explain the relatively low IASCC susceptibility in alloy ES and the lack of susceptibility in alloy KS. In the four-point bend test, a well-developed DC network ( 788 $\mathrm{DCs} / \mathrm{mm}^{2}$ ) formed on the ES01 sample surface prior to crack initiation, while a maximum of only $\sim 41$

$\mathrm{DCs} / \mathrm{mm}^{2}$ was observed prior to crack initiation on alloy AS at a similar irradiation dose. This comparison shows the IASCC-enhancing effect of MnS inclusions, as only small oxide inclusions were present in alloy ES. Comparing the SCC behavior of alloys ES and KS, however, reveals that small oxide inclusions were not responsible for crack initiation, as they were also present in alloy KS. Due to the dependence of IASCC on DCs $[5,27,29]$ and the effect of discontinuous DC-GB intersections observed by McMurtrey et al. [7], DC parameters were further compared among the alloys. Observations from both $288^{\circ} \mathrm{C} \mathrm{Ar}$ and NWC were combined in this analysis, as the test environment had little effect on the measured DC parameters.

Discontinuous DCs cause high local stress concentration and are significantly more likely to result in crack initiation than sites where DCs transmit across the GB (continuous DCs) [6,7]. To compare the propensity for alloys in the four-point bend test to form discontinuous DC-GB intersections, the 'channel transmission frequency' (slip transmission site density normalized by the DC density at a particular strain) was determined for all three alloys and shown in Fig. 13. Alloy KS (with a high Ni concentration) was the most likely to transmit DCs across GBs at all levels of applied strain, which likely limited stress accumulation at DC-GB intersections and prevented IASCC susceptibility in this alloy. This observation agrees with the mechanism of crack initiation determined by McMurtrey et al. [7], but it must be noted that only a small fraction of discontinuous DC-GB intersections formed cracks in McMurtrey's study $[5,7]$. Therefore, only certain sites were able to exceed the stress requirement for IASCC initiation. This 
was also the case in alloy ES, as numerous discontinuous DC-GB intersections were observed prior to crack initiation. A limited number of DC-transmitting GBs also formed crack initiation sites in McMurtrey's study [5,7], but neutron-irradiated alloy ES would have likely failed prior to accumulating the stress concentration necessary for crack initiation at these locations. Locations of slip transmission did not cause crack initiation in alloy KS, which was strained to nearly $10 \%$ in the four-point bend test and did not display any IASCC initiation sites after failure in the CERT test [16]. This resistance to IASCC in high Ni alloys has also been observed in proton-irradiated SS by McMurtrey and Was [57] and Cookson [51], and in neutron irradiated SS by Kodama et al. [58]. It is apparent that GBs in high Ni alloys are inherently less susceptible to IASCC, regardless of local DC behavior, but additional work is necessary to understand why.

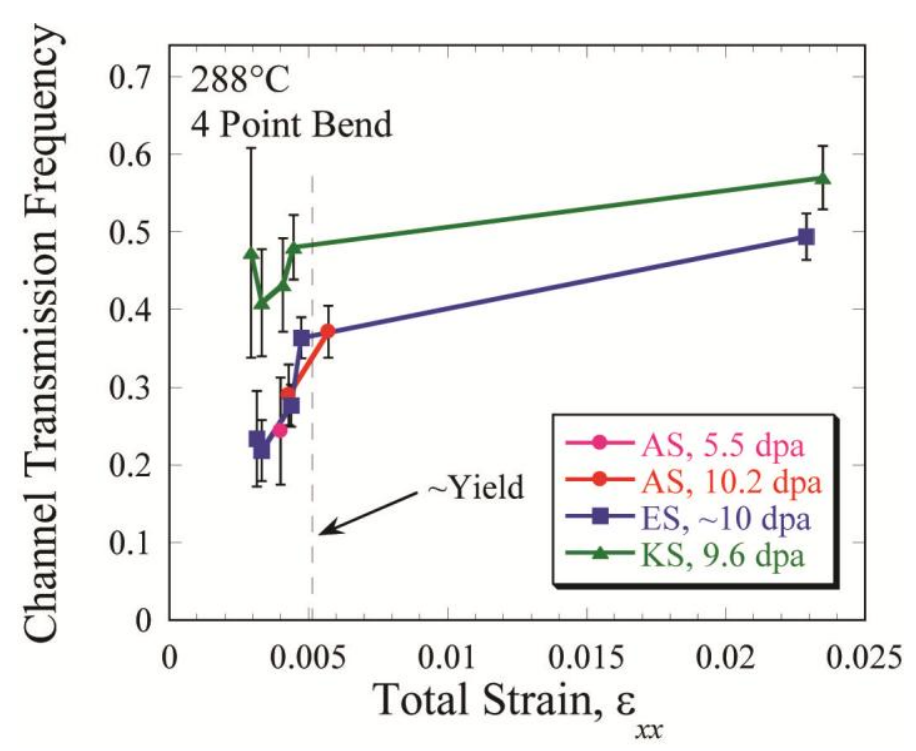

Fig. 13. Channel transmission frequency (slip transmission site density normalized by total DC density) for each alloy after four-point bend tests in $288^{\circ} \mathrm{C} \mathrm{Ar}$ and NWC.

In summary, IASCC initiation in neutron irradiated alloys is affected by stress accumulation at GBs due to discontinuous DC-GB intersections, consistent with the mechanism suggested by McMurtrey [7]. Agreement was also observed with previous CERT tests performed under the same conditions [16] (aside from minor differences in stress-strain state), validating observations made in the bend test and enhancing the understanding of how cracks initiate in CERT tests. In both CERT and bend tests, alloy AS had the highest IASCC susceptibility of the three alloys due to the presence of $\mathrm{MnS}$, which created an aggressive environment and high stress condition when intersected by DCs as discussed previously. Susceptibility in this alloy increased with irradiation dose as a result of DC formation at lower applied stress. Neither alloy ES nor KS possessed MnS inclusions, rendering them less susceptible to IASCC than alloy AS. The propensity of alloy ES to form discontinuous DC-GB intersections increased the local stress concentration 
at these sites, allowing rupture of the protective oxide at the GB and initiating IASCC. The intermediate relative susceptibility of alloy ES was consistent with observations from the CERT test [16]. Alloy KS had a high propensity to transmit DCs across GBs, preventing stress accumulation at the GB and suppressing IASCC initiation. The high propensity for alloy KS to form continuous DCs was a likely factor in the observation of $100 \%$ ductile failure under these test conditions in the CERT test [16].

Observations from four-point bend tests have clarified several key factors in the IASCC initiation process, but opportunities for future work are also evident. A primary question which still remains is why DCs are able to form at lower applied stress in high dose material. Four-point bend test results have shown that this occurs, but in material with innately high IASCC susceptibility due to the presence of MnS inclusions. For more complete understanding of how DCs affect crack initiation, similar experiments are necessary using materials without these inclusions (such as alloy ES) at different levels of irradiation dose. A similar decreasing stress dependence of IASCC initiation would provide additional evidence supporting the effect of DCs in the IASCC initiation process, and how increased localized deformation enhances susceptibility. Furthermore, more carefully controlled deformation experiments could also help to link DC initiation with the irradiation-induced defect microstructure. Advances in the understanding of DC formation and how DCs affect IASCC initiation coupled with physical measurements of stress accumulation at DC-GB intersections (such as those performed by McMurtrey et al. [6]) will ultimately provide a clear mechanistic understanding of the IASCC initiation process.

\section{Conclusions}

A novel four-point bend SCC experiment provided the opportunity to observe IASCC crack initiation and led to the following conclusions:

- Dislocation channeling is a major factor influencing the susceptibility to IASCC initiation in CP 304L alloy AS and HP 304L alloy ES.

- Dislocation channels were observed prior to crack initiation and at crack initiation sites in 5 of 6 cases on alloy AS samples. The stress to initiate DCs was less than the stress to initiate IASCC at each irradiation dose in CP 304L alloy AS. Therefore, it is likely that discontinuous DCs control the stress dependence of IASCC initiation.

- MnS inclusions enhance susceptibility to IASCC initiation in CP 304 alloy AS due to their dissolution during NWC exposure. At all IASCC initiation sites, an oxide cap was formed, occluding the inclusion site and creating a crevice condition in which deaeration resulted in an acidified environment within the crevice. Stress concentration caused by a favorably oriented 
grain boundary and the inclusion led to the formation of a discontinuous dislocation channel, which further increased the local stress concentration, resulting in crack initiation.

- HP 304L alloy ES was less susceptible to IASCC than CP 304L alloy AS due to a lack of MnS inclusions, but IASCC initiation was still possible in this alloy because stress concentrations at discontinuous dislocation channel - grain boundary intersections were able to rupture the surface oxide and nucleate cracking.

- HP 304L+Ni stainless steel (alloy KS) was not susceptible to IASCC because this alloy had no $\mathrm{MnS}$ inclusions and also had a high propensity to transmit dislocation channels across grain boundaries, thus preventing stress accumulation at DC-GB sites.

\section{Acknowledgements}

Support for this project was provided by funding from the Electric Power Research Institute (contract number 10003872) and the United States Department of Energy Light Water Reactor Sustainability Program (contract number 4000136608). The authors would like to acknowledge the use of facilities in the Irradiated Material Testing Laboratory at the University of Michigan. Additional thanks is also due to Alex Flick for assistance with experimental setup, Maxim Gussev for assistance with sample preparation and data collection, the technical staff at the Low Activity Materials Development and Analysis Laboratory at Oak Ridge National Laboratory, and the support of radiation safety services at the University of Michigan.

\section{References}

[1] Z. Jiao, G.S. Was, J. Nucl. Mater. 382 (2008) 203.

[2] K. Fukuya, J. Nucl. Sci. Technol. 50 (2013) 213.

[3] K. Fukuya, K. Fujii, in:, 12th Int. Conf. Environ. Degrad. Mater. Nucl. Power Syst. - Water React., 2005, pp. 389-393.

[4] K. Fukuya, H. Nishioka, K. Fujii, T. Miura, T. Torimaru, J. Nucl. Mater. 417 (2011) 958.

[5] M.D. McMurtrey, G.S. Was, L. Patrick, D. Farkas, Mater. Sci. Eng. A 528 (2011) 3730.

[6] M.D. McMurtrey, G.S. Was, B. Cui, I. Robertson, L. Smith, D. Farkas, Int. J. Plast. (2014) 1. 
[7] M.D. Mcmurtrey, B. Cui, I. Robertson, D. Farkas, G.S. Was, Curr. Opin. Solid State Mater. Sci. 19 (2015) 305.

[8] H. Nishioka, K. Fukuya, K. Fujii, Y. Kitsunai, J. Nucl. Sci. Technol. 45 (2008) 274.

[9] R.W. Bosch, M. Vankeerberghen, R. Gérard, F. Somville, J. Nucl. Mater. 461 (2015) 112.

[10] K. Fukuya, M. Nakano, K. Fujii, T. Torimaru, J. Nucl. Sci. Technol. 41 (2004) 673.

[11] K. Fukuya, S. Shima, H. Kayano, M. Narui, J. Nucl. Mater. 191-194 (1992) 1007.

[12] M. Kodama, J. Morisawa, S. Nishimura, K. Asano, S. Shima, K. Nakata, J. Nucl. Mater. 212-215 (1994) 1509.

[13] M. Kodama, K. Fukuya, H. Kayano, in:, A.S. Kumar, D.S. Gelles, R.K. Nanstad, E.A. Little (Eds.), Eff. Radiat. Mater. 16th Int. Symp., American Society for Testing and Materials, Philadelphia, 1993.

[14] G. Furutani, N. Nakajima, T. Konishi, M. Kodama, J. Nucl. Mater. 288 (2001) 179.

[15] R. Katsura, J. Morisawa, M. Kodama, S. Nishimura, S. Suzuki, S. Shima, M. Yamamoto, in:, Proc. 6th Int. Symp. Environ. Degrad. Mater. Nucl. Power Syst. - Water React., 1993, pp. 625632.

[16] K.J. Stephenson, G.S. Was, J. Nucl. Mater. 444 (2014) 331.

[17] K.J. Stephenson, G.S. Was, in:, 17th Int. Conf. Environ. Degrad. Nucl. Power Syst., 2015.

[18] K.J. Stephenson, The Role of Dislocation Channeling in IASCC Initiation of Neutron Irradiated Austenitic Stainless Steel, University of Michigan, 2016.

[19] B.W. Arey, D.G. Atteridge, S.M. Bruemmer, Production of Tailored Alloys to Isolate Metallurgical Variables Promoting IASCC, Palo Alto, CA, 2007.

[20] J.P. Massoud, P. Dubuisson, P. Scott, V.K. Chamardine, CIR II Program: Description of the Boris 6 and 7 Experiments in the BOR-60 Fast Breeder Reactor 1011787, EPRI, Palo Alto, CA, 2005. 
[21] D. Edwards, E. Simonen, S. Bruemmer, P. Efsing, in:, Proc. 12th Environ. Degrad. Mater. Nucl. Power Syst. - Water React., 2005, pp. 419-428.

[22] J.C. Heap, Thermal Stresses in Concentrically Heated Hollow Cylinders, Argonne, IL, 1960.

[23] K.J. Stephenson, G.S. Was, J. Nucl. Mater. 456 (2015) 85.

[24] M.P. Fay, P. a Shaw, J. Stat. Softw. 36 (2010) 1.

[25] D.W. Hosmer, S. Lemeshow, Applied Survival Analysis: Regression Modeling of Time to Event Data, 1999.

[26] O.K. Chopra, a. S. Rao, J. Nucl. Mater. 409 (2011) 235.

[27] Z. Jiao, G.S. Was, J. Nucl. Mater. 408 (2011) 246.

[28] Z. Jiao, J.T. Busby, R. Obata, G.S. Was, in:, T.R. Allen, P.J. King, L. Nelson (Eds.), Proc. 12th Environ. Degrad. Mater. Nucl. Power Syst. - Water React., TMS, Salt Lake City, Utah, 2005, pp. 379-388.

[29] E. a. West, M.D. McMurtrey, Z. Jiao, G.S. Was, Metall. Mater. Trans. A 43 (2011) 136.

[30] D.J. Edwards, A. Schemer-Kohrn, S. Bruemmer, Characterization of Neutron-Irradiated 300Series Stainless Steels 1009896, EPRI, Palo Alto, CA, 2006.

[31] D.J. Edwards, S.M. Bruemmer, Characterization of CIR II Irradiated Stainless Steels EPP19021/C9406, Palo Alto, CA, 2008.

[32] L. Tan, J.T. Busby, J. Nucl. Mater. 443 (2013) 351.

[33] G.E. Lucas, J. Nucl. Mater. 206 (1993) 287.

[34] G.S. Was, Fundamentals of Radiation Materials Science, Springer, New York, NY, 2007.

[35] Z. Jiao, G.S. Was, J. Nucl. Mater. 407 (2010) 34.

[36] P. Hurst, D.A. Appleton, P. Banks, A.S. Raffel, Corros. Sci. 25 (1985) 651. 
[37] H. Hanninen, W. Cullen, M. Kemppainen, Corrosion 46 (1990) 563.

[38] J.T. Busby, G.S. Was, The Use of Proton Irradiation to Determine IASCC Mechanisms in Light Water Reactors: Phase 2: Commercial Alloys 1009898, EPRI, Palo Alto, CA, 2005.

[39] B. Bavarian, Z. Szklarska-Smialowska, D.D. Macdonald, Corrosion 38 (1982) 604.

[40] M.P. Mueller, Corrosion 38 (1982) 431.

[41] X.Y. Zhou, J. Congleton, a. Bahraloloom, Corrosion 54 (1998) 898.

[42] B. Beverskog, I. Puigdomenech, Corros. Sci. 38 (1996) 2121.

[43] F.P. Ford, D.F. Taylor, P.L. Andresen, R.G. Ballinger, Corrosion-Assisted Cracking of Stainless and Low-Alloy Steels in LWR Environments, 1987.

[44] P.L. Andresen, C.L. Briant, Corrosion 45 (1989) 448.

[45] F.P. Ford, Corrosion 52 (1996) 375.

[46] T. Shoji, H. Takahashi, S. Aizawa, M. Saito, in:, Proc. 3rd Environ. Degrad. Mater. Nucl. Power Syst. - Water React., 1988, pp. 251-259.

[47] W.E. Ruther, W.K. Soppet, T.F. Kassner, Corros. Sci. 44 (1988) 791.

[48] Z. Jiao, G.S. Was, J.T. Busby, in:, 13th Int. Conf. Environ. Degrad. Mater. Nucl. Power Syst. Water React., Whistler, British Columbia, 2007, pp. 1-11.

[49] F. Meng, J. Wang, E.H. Han, W. Ke, Corros. Sci. 52 (2010) 927.

[50] J. Tan, X. Wu, E. Han, W. Ke, X. Liu, F. Meng, X. Xu, Corros. Sci. 88 (2014) 349.

[51] J.M. Cookson, The Role of Oxides and Impurities in Proton Irradiation Assisted Stress Corrosion Cracking of Stainless Steels, University of Michigan, 1996.

[52] M. Kamaya, Y. Kawamura, T. Kitamura, Int. J. Solids Struct. 44 (2007) 3267.

[53] K.G. Field, Y. Yang, T.R. Allen, J.T. Busby, Acta Mater. 89 (2015) 438. 
[54] L. Tan, K. Field, Personal communication. (2013).

[55] S.M. Bruemmer, B.W. Arey, L. a Charlot, Corrosion 48 (1992) 42.

[56] A.J. Jacobs, C.M. Shepherd, G.E.C. Bell, G.P. Wozadlo, in:, Proc. 5th Int. Symp. Environ. Degrad. Mater. Nucl. Power Syst. - Water React., 1991, pp. 917-934.

[57] M.D. McMurtrey, G.S. Was, in:, 15th Int. Conf. Environ. Degrad. Nucl. Power Syst., 2011, pp. 1383-1394.

[58] M. Kodama, K. Fukuya, H. Kayano, in:, 16th Int. Symp. No Eff. Radiat. Mater., ASTM International, Aurora, CO, 1994, pp. 889-901. 